\title{
The iSEARCH Trials of oral Sildenafil in labour: Protocol for a randomised trial in 3,200 Australian women and Rationale for an Individual Participant Data Prospective Meta-Analysis of trials in 14,000 women in high-income countries and a mega-trial of 50,000 women in low or middle-income countries.
}

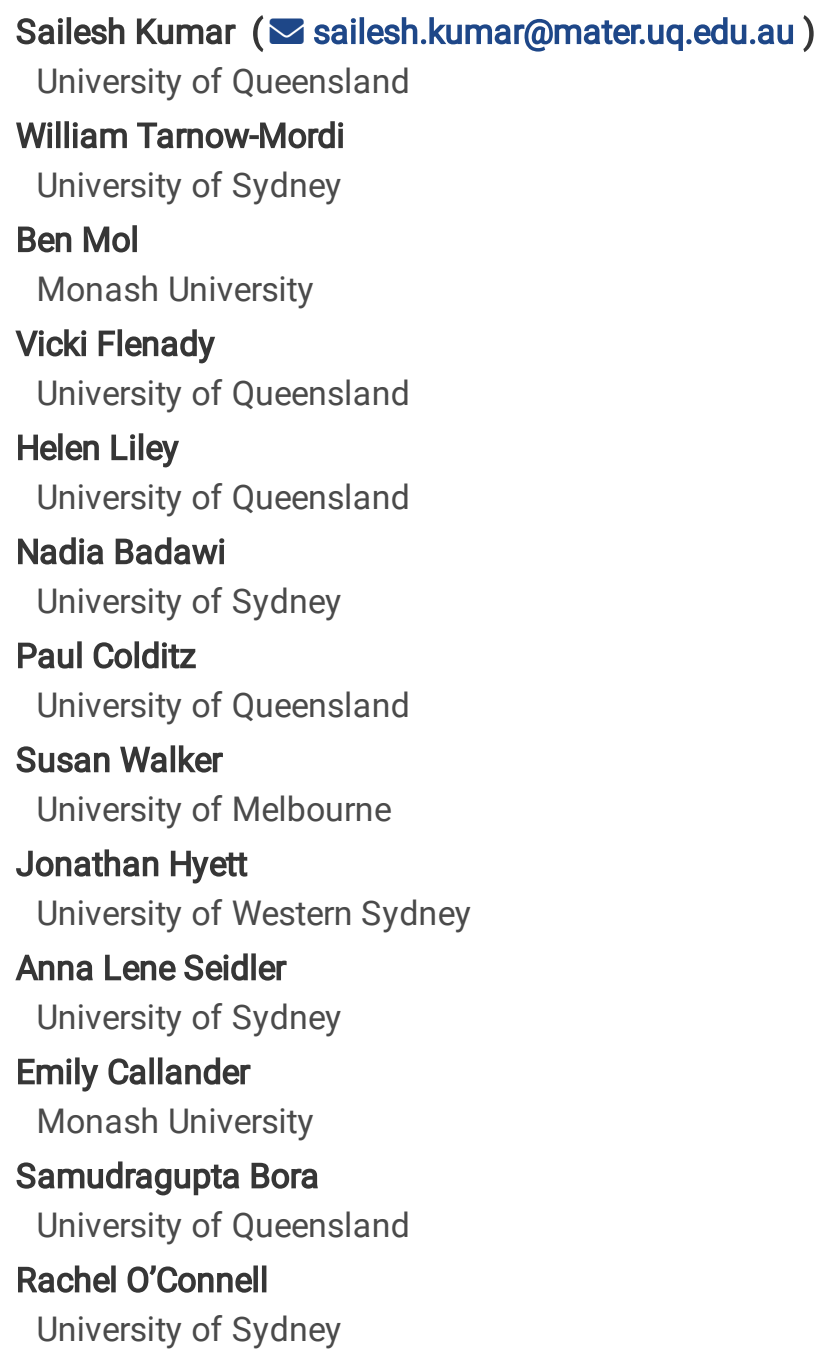

Method Article

Keywords: sildenafil, birth asphyxia, labour, pregnancy, clinical trial, prospective meta analysis, neonatal, perinatal 


\section{Abstract}

\section{Introduction}

We showed in a Phase 2 RCT that oral Sildenafil during term labour halves the need for operative birth for suspected fetal distress. To assess if Sildenafil reduces adverse perinatal outcomes, we describe a Phase 3 RCT (iSEARCH) and the rationale for an individual participant data prospective meta-analysis (IPD PMA) of RCTs in high-income countries and a mega-trial in low-and middle-income countries.

\section{Methods and analysis}

iSEARCH will enrol 3200 women in term labour, yielding $>80 \%$ power to determine whether oral administration of up to three 50 $\mathrm{mg}$ doses of Sildenafil versus placebo reduces the relative risk of intrapartum hypoxia, determined as a primary composite endpoint of ten perinatal outcomes, by $35 \%$ (from $7 \%$ to $4.55 \%$ ). We also outline the rationale for (i) an IPD PMA of RCTs in about 14,000 women in Australia and other countries with low perinatal mortality rates which would yield $90 \%$ power to test if oral Sildenafil achieves a more moderate and realistic reduction of $20 \%$ in the relative risk of this composite endpoint and (ii) a megatrial in about 50,000 women in countries with moderate or high perinatal mortality rates to test if oral Sildenafil achieves a similarly moderate and realistic $20 \%$ reduction in the relative risk of a composite endpoint comprising intrapartum stillbirth or 7day neonatal mortality. Secondary aims will be to evaluate the rate of operative birth for fetal distress, its cost-effectiveness, and developmental and educational outcomes.

\section{Article Summary}

\section{Strengths and limitations of this project}

- The intrapartum SildEnafil to Avert the Risks of Contraction-induced Hypoxia (iSEARCH) Trials will evaluate maternal oral Sildenafil for management of labour at term in Australia and in an IPD PMA of concurrent, similar trials in countries with low perinatal mortality rates and in a mega-trial in countries with moderate or high perinatal mortality rates. An IPD PMA is like a mega-trial, but less expensive for individual funders and represents a key conceptual advance in achieving large-scale randomised perinatal evidence which is more affordable for individual funders but can facilitate faster improvements in practice and outcomes.

- We describe the protocol of iSEARCH, the first Phase 3 RCT, which was funded to enrol 3,200 Australian women for AUD\$3.4 million, the maximum sum which the investigators considered financially feasible to request in a single grant. However, this sample size only has $>80 \%$ power to show an optimistic 35\% reduction in the relative risk of a ten-component primary composite endpoint reflecting intrapartum hypoxia. Hence the rationale for (i) an IPD PMA of similar pragmatic RCTs in 14,000 women in Australia and other countries with low perinatal mortality rates, with 90\% power to show a more moderate and realistic 20\% relative risk reduction of this ten component endpoint and (ii) a mega-trial in 50,000 women in countries with moderate or high perinatal mortality rates, with $\sim 90 \%$ power to show a similarly moderate and realistic $\sim 20 \%$ relative risk reduction in a primary composite outcome of intrapartum stillbirth or 7 day neonatal mortality.

- An international Independent Data Monitoring Committee will advise the Trial Management Committees of RCTs in the IPD PMA and mega-trial if early evidence emerges of a difference in either primary composite endpoint between study arms beyond reasonable doubt and, in their opinion, this evidence will change the behaviour of those who are already aware of other trials in this area. Such advice would allow individual Trial Management Committees to stop or modify enrolment early.

- The IPD PMA will have risk of bias assessed by Cochrane RoB-2 criteria, ${ }^{1}$ follow PRISMA-IPD Guidelines ${ }^{2}$ and will be registered in the PROSPERO ${ }^{3}$ Database. Certainty of evidence will be appraised by GRADE ${ }^{4}$ (Grading of Recommendations Assessment, Development and Evaluation).

- Parental consent will be sought for linkage with long-term health and educational outcomes, where available. 
- The trials will be highly streamlined to facilitate rapid, large-scale enrolment with minimal data collection, as in the RECOVERY Trial ${ }^{5}$ and in large simple trials in suspected myocardial infarction. ${ }^{6-9}$

\section{Introduction}

Fetal distress in labour usually reflects pre-existing placental impairment ${ }^{10} 11$ which reduces the capacity of the fetus to cope with the stress of uterine contractions. ${ }^{12}$ In many term pregnancies, uterine blood flow falls by $60 \%$ during contractions, ${ }^{13}$ provoking fetal distress. Fetal decompensation occurs ${ }^{14}$ if there is insufficient time for placental reperfusion to occur between contractions. $^{10}$

Suspected fetal distress due to hypoxia in labour is a key factor in $23 \%$ of emergency caesarean births in Australia. ${ }^{15} \mathrm{Hypoxic}$ fetal injury can lead to intrapartum stillbirth and severe neonatal morbidity including neonatal encephalopathy and cerebral palsy in the long term. ${ }^{16} 1718$ Intrapartum hypoxia-ischemia causes 1 in 3 of cases of neonatal encephalopathy in countries with low perinatal mortality rates (PMR) and almost $60 \%$ of cases in countries with moderate or high PMRs. ${ }^{19}$ Other than emergency operative birth [Caesarean section or instrumental (forceps or vacuum) vaginal birth], options are limited.

Sildenafil Citrate is a phosphodiesterase- 5 inhibitor that enhances the bioavailability of Nitric Oxide (NO) by inhibiting cyclic guanosine monophosphate degradation. Increased tissue NO levels improve vasodilatation and reduce vascular dysfunction secondary to vasoconstrictors and antiangiogenic factors. ${ }^{20} 21$ Sildenafil preferentially dilates pelvic blood vessels and increases utero-placental blood flow. ${ }^{22}$ Our systematic review of 10 obstetric randomised controlled trials (RCTs) of 1,090 women found that phosphodiesterase- 5 inhibitor use in pregnancy was associated with a reduction in the RR of operative birth for intrapartum fetal distress (RR 0.58, 95\% $\mathrm{Cl} 0.38-0.88){ }^{23}$

Our Phase $2 \mathrm{RCT}^{24}$ (RIDSTRESS) tested whether, compared to placebo, Sildenafil lowered rates of emergency operative birth for fetal distress in term labour. Sildenafil reduced (i) the relative risk (RR) of operative birth for fetal distress by $51 \%$ [(RR $0.49,95 \% \mathrm{Cl}$ 0.33-0.73), $p=0.0004$; Number Needed to Treat for Benefit $=5(3-11)]$ and (ii) rates of pathological fetal heart rate $(F H R)$ patterns ( $15 \%$ vs. $32 \%$; RR $0.48,95 \% \mathrm{Cl} 0.31-0.75, \mathrm{p}=0.0009)$. RIDSTRESS, however, lacked power to show a statistically significant improvement in neonatal outcomes, which would strengthen the rationale for Sildenafil treatment in labour.

The first Australian intrapartum SildEnafil to Avert the Risks of Contraction-induced Hypoxia (iSEARCH) trial began on 7th September 2021. It is the world's first Phase 3 RCT to re-purpose Sildenafil by evaluating whether, compared to placebo, it improves perinatal outcome, measured as a composite of ten adverse fetal or neonatal outcomes, broadly similar to the primary composite outcome of the ARRIVE trial in term pregnancies, ${ }^{25}$ in 3200 women by reducing the risk of intrapartum fetal distress. It is funded by the Australian Medical Research Future Fund and will run until August 2024. However, the $35 \%$ reduction in the relative risk of its primary composite outcome which it postulates is nearly twice as large as the $20 \%$ relative reduction in the tencomponent composite outcome which was observed in the ARRIVE trial, which enrolled nearly twice as many $(N=6,106)$ women. ${ }^{25}$ This putative $35 \%$ relative risk reduction is therefore likely to reflect 'optimism bias ${ }^{26-29}$ and the iSEARCH trial has less

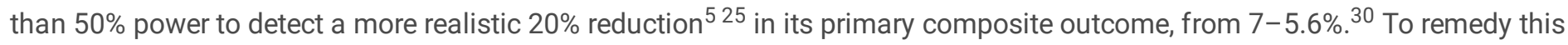
limitation, the iSEARCHRCT will be nested in an Individual Participant Data Prospective Meta-Analysis (IPD PMA) comprising a second similar trial in Australia and in other countries with low perinatal mortality rates, using the same primary ten-component composite endpoint in 14,000 women, for which further Australian and international funding will be sought.

Through national and international collaboration in the COVID-19 pandemic, the multi-arm, multi-stage adaptive UK RECOVERY 5

and WHO SOLIDARITY ${ }^{31}$ platform trials randomised over 20,000 patients in less than six months ${ }^{31} 32$ to test the effects of six treatments on mortality and major morbidity in hospitalized COVID-19 patients. RECOVERY showed that dexamethasone achieved about a $20 \%$ reduction in the age -adjusted relative risk of mortality. ${ }^{5}$ The inclusion of the RECOVERY trial in a subsequent $\mathrm{PMA}^{53}$ rapidly confirmed that administration of systemic corticosteroids, compared with usual care or placebo, was associated with lower 28-day all-cause mortality thus confirming its efficacy for the treatment of critically ill patients with 
suspected or confirmed COVID-19 infection. Such studies ${ }^{52-34}$ have important implications for how future trials in all specialties are designed and run.

The ideal way to achieve sufficiently large numbers to detect moderate reductions in mortality and/or major morbidity is through a single mega-trial ${ }^{34}$ but, if that is not feasible, a PMA of similar, concurrent trials like the STRIDER (Sildenafil TheRapy In Dismal prognosis Early-onset intrauterine growth Restriction) Consortium, ${ }^{35}$ but overseen by a single data monitoring committee, provides an important advance towards realising this goal. ${ }^{36}$

We therefore outline the rationale for (i) an IPD PMA of RCTs in 14,000 women in high income countries with low perinatal mortality rates, including iSEARCH, to test the effect of Sildenafil on a primary composite endpoint of ten perinatal outcomes and (ii) a mega-trial in 50,000 women in countries with moderate or high perinatal mortality rates to test its effect on a primary composite endpoint of two adverse outcomes (intrapartum stillbirth or 7-day neonatal mortality).

\section{Methods And Analysis}

\section{The first Australian Phase 3 iSEARCH RCT.}

\section{Primary Research Question}

Does maternal oral Sildenafil in labour, compared with placebo, reduce the primary composite endpoint of ten adverse neonatal outcomes? (Table 1)

\section{Secondary Research Questions}

(a) Does maternal oral Sildenafil in labour reduce the rate of the secondary outcome of emergency operative birth for fetal distress?

(b) Is it more cost effective?

Study Design: This is a two-arm parallel, randomised (1:1), placebo-controlled, double-blind multicentre superiority trial of Sildenafil vs. placebo for women in labour at term ( $\geq 37^{+0}$ weeks gestation).

\section{Aim}

This study aims to test the hypotheses that up to 3 doses of oral $50 \mathrm{mg}$ Sildenafil (vs. placebo) is safe and will improve perinatal and maternal outcomes related to intrapartum hypoxia.

\section{Primary objective:}

To evaluate whether, compared with placebo, Sildenafil reduces the relative risk of the composite perinatal endpoint by $35 \%$, from 7-4.55\%. The composite endpoint comprises the ten components shown in Table 1.

\section{Secondary objectives:}

1. To evaluate whether Sildenafil results in a reduction of the RR of each individual component of the composite primary outcome.

2. To evaluate whether Sildenafil results in a reduction of the RR of Caesarean section or instrumental vaginal birth for fetal distress by $25 \%$ (from $20-15 \%$ ).

3. To evaluate whether Sildenafil is more cost-effective than placebo.

\section{Sample Size}

The incidence of the composite adverse outcome is estimated at $7 \%$ based on data from several of the participating hospitals, the ARRIVE RCT, ${ }^{25}$ and the Australian and New Zealand Neonatal Network. ${ }^{37}$ To detect a $35 \%$ reduction from $7-4.55 \%$ for an alpha of 0.05 and $>80 \%$ power with $2 \%$ drop-out and $5 \%$ loss to follow up in each arm, needs about 3,200 women (Table 2, 
scenario 1). This sample size also yields $>90 \%$ power to detect a $25 \%$ reduction for the secondary outcome of Caesarean section or instrumental vaginal birth for fetal distress.

\section{Study population}

Inclusion criteria:

1. Women with singleton or dichorionic twin pregnancies, planning vaginal birth at term ( $\geq 37^{+0}$ weeks gestation).

2. Age $\geq 18$ years.

3. Willing and able to comply with all study requirements.

4. Signed, written informed consent.

Exclusion criteria:

1. A woman should not be enrolled if the responsible clinician or the woman are, for any medical or nonmedical reasons, reasonably certain that Sildenafil would be inappropriate for her in comparison with no treatment or some other treatment that could be offered outside the trial. ${ }^{38}$

2. Monochorionic twins, triplets or higher order multiple births, which are generally delivered electively before term.

3. Women who are taking any type of nitrate drug therapy or who utilize short-acting nitrate-containing medications during labour (such as sodium nitroprusside, bosentan, fosamprenavir and ritonavir combination, hepatic enzyme inhibitors CYP3A4 (including itraconazole, ketoconazole, ritonavir, cimetidine, erythromycin, saquinavir, darunavir), or hepatic enzyme substrates (CYP3A4), medications used to treat pulmonary arterial hypertension, and other phosphodiesterase type 5 inhibitors, due to the risk of potentially life-threatening hypotension. ${ }^{39}$

4. Severe hepatic or renal impairment. ${ }^{39}$

\section{Screening, registration and randomisation}

All women attending antenatal clinics in participating hospitals from $\geq 34^{+0}$ weeks will be screened for eligibility by study midwives. Women who wish to participate will be registered in an online trial registration database, as detailed in the Study Manual (e-supplement 1). Once registered, each woman is assigned a unique study number and receives routine obstetric care until the onset of spontaneous labour or induction of labour, when randomisation is undertaken. Individuals may only be registered and randomised once. Randomisation is undertaken after the responsible clinician (midwife or obstetrician) has again confirmed that the woman is eligible to participate. If an eligible woman presents for the first time in labour, screening, registration and randomisation are done together. Once registration and randomisation are completed, the participant is assigned a treatment arm. A log at each site will record the number of women screened for eligibility, those eligible, those approached and those consented. If a woman declines participation, a reason is recorded if she agrees to provide one.

At registration, women will be invited to consent to participate in childhood neurodevelopmental follow-up and for data to be extracted from Medicare Benefits Schedule and Pharmaceutical Benefits Schemes claims records for herself and her infant and from the Australian cerebral palsy register. If she consents, contact details will be recorded and follow-up assessment will be performed as described below. If consent is declined or withdrawn before follow-up takes place (2-3 years corrected age), no further contact will take place.

\section{Study Treatments}

The study intervention is oral Sildenafil. The control intervention is placebo. Study treatment only begins after transfer to the labour ward either in spontaneous labour or for induction of labour (artificial rupture of membranes +/- oxytocin). Women are given the first dose by the attending midwife in the labour ward. Women receive Sildenafil $50 \mathrm{mg}$ or identical placebo orally every 8 hours to a maximum of three doses, from identical matched treatment packs supplied by pharmacy.

\section{Management of Labour and Puerperium}

Continuous electronic intrapartum FHR monitoring will be performed in all women. Umbilical artery cord pH will be measured in all women after birth. Classification of FHR abnormalities is based on the Royal Australian and New Zealand College of 
Obstetricians and Gynaecologists guidelines. ${ }^{46} \mathrm{In}$ a subset of women, $20 \mathrm{ml}$ of blood will be collected for assay of soluble Fmslike tyrosine kinase-1 (sFlt-1) and Placental Growth Factor (PIGF) levels. These women will also have an ultrasound scan performed to assess the fetoplacental circulation and liquor volume before and after treatment. The ultrasound data and maternal sFIt-1 and PIGF levels will allow post-hoc subgroup analysis to identify cohorts at risk of fetal distress that might derive greater benefit from Sildenafil treatment. Otherwise, intrapartum management will be in accordance with local hospital guidelines.

To detect possible persistent pulmonary hypertension of the newborn, all infants will also receive routine oxygen saturation screening to detect hypoxemia, generally 24-48 hours after birth but, if necessary, four hours after birth. Infants with oxygen saturations of $>95 \%$ are very unlikely to have major congenital heart or significant pulmonary disease, including persistent pulmonary hypertension of the newborn. Infants with oxygen saturations $\leq 95 \%$ will receive further assessment by the paediatric team which may include echocardiography.

\section{Trial Outcomes}

In-hospital maternal and neonatal outcome events occurring from randomisation to discharge home will be collected from medical records into electronic Case Report Forms. Assessments of outcome will be blinded to treatment allocation. Except for 28-day neonatal mortality, all primary outcome data will be routinely available before discharge and collected electronically. There are no formal study assessments visits. Research midwives will contact women 30 days after discharge to ascertain further relevant issues. Childhood follow up will be conducted using parent report questionnaires and by linkage with educational databases and cerebral palsy registers. ${ }^{40-42}$

\section{Data Analysis}

A detailed Statistical Analysis Plan will be published before data analysis begins ${ }^{43}$, as will a detailed health economic evaluation protocol. Primary and secondary analyses will adhere to an intention-to-treat basis using generalised linear models (binary or normal). Intervention effect will be presented as relative risk or mean difference, as appropriate, with $95 \%$ confidence intervals. Primary analyses will be unadjusted. Numbers needed to treat to prevent one adverse outcome will be calculated. Where there are differences in baseline characteristics between the two treatment groups that might be associated with outcomes, secondary analyses of the primary outcome will be carried out using multiple (log-binomial) regression. Reporting will follow CONSORT ${ }^{44}$ and TRIPOD ${ }^{45}$ guidelines.

Secondary outcomes include each of the ten individual components of the primary composite outcome (Table 1). P values adjusted for these ten comparisons will be derived using the Benjamin-Hochberg procedure, limiting the false discovery rate to $5 \% .{ }^{46}{ }^{47}$ Results of other endpoint, subgroup and sensitivity analyses will be interpreted in proper context and with due consideration of the risk of Type I error. Interpretation of statistical evidence will also consider the recommendations of Pocock et al. ${ }^{48} 49$

\section{Monitoring Safety}

The international STRIDER RCTs used daily maternal Sildenafil doses of $75 \mathrm{mg}$ in pregnant women with severe fetal growth restriction between 20 and 30 weeks gestation for up to 10 weeks, i.e. cumulative doses of up to 5,250 mg. ${ }^{50} 51$ In 2019 , The Dutch STRIDER trial was stopped on the advice of the Data Safety Monitoring Board due to an increase in persistent pulmonary hypertension of the newborn (PPHN) with a non-significant increase in neonatal deaths in the Sildenafil group. ${ }^{52}$ PPHN occurred in 16 neonates $(18.8 \%)$ in the Sildenafil group vs. 4 neonates $(5.1 \%)$ in the placebo group (relative risk, $3.67 ; 95 \% \mathrm{Cl}, 1.28-10.51$; $P=0.008)$. A subsequent meta-analysis of 329 participating women in all available trials showed no difference in neonatal deaths. ${ }^{53}$ However it was recommended that Sildenafil not be prescribed outside of clinical trials. ${ }^{35}$ The indication and cumulative dosage of Sildenafil in the iSEARCH trial are very different from the STRIDER trials as we will only use a maximum $150 \mathrm{mg}$ in women at term, which is thirty five times lower. PPHN will be monitored as one of ten components of the primary composite endpoint by the independent data and safety monitoring board, as outlined below. 


\section{The Australian iSEARCH RCT Independent Data and Safety Monitoring Board}

The IDSMC will review interim data on the primary outcome, specified adverse events and other evidence after $50 \%$ of recruitment or whenever they deem appropriate, as recommended by Peto, Pocock and others. ${ }^{54-56}$ There will be no adjustment to alpha for interim analyses.

\section{Interim analyses of the primary composite outcome}

The IDSMC will advise the TMC if in their view there is proof beyond reasonable doubt of net benefit or harm for the primary composite endpoint, for example employing a commonly used formal threshold of $\mathrm{P}<0.001$ for nominal significance, as recommended by Geller and Pocock. ${ }^{56}$

\section{Interim analyses of mortality}

The IDSMC will advise the TMC if in their view there is a difference in mortality due to intrapartum stillbirth and/or 28-day neonatal mortality identified as a deviation from the null indicated by a Haybittle-Peto boundary of 3 standard errors from the null, which is equivalent to $\mathrm{P}<0.0027,5455$ which would be needed to justify recommending early stopping.

\section{Overarching International Data Monitoring Committee}

The Chair or a representative of the Australian iSEARCH trial will serve on an overarching international data monitoring committee which will receive regular primary outcome data from all participating trials, which may also recommend early stopping if there is evidence from pooled data with high confidence, e.g. a deviation in the primary outcome equivalent to $\mathrm{P}<0.001^{56}$, or a deviation in mortality due to intrapartum stillbirth and/or 28 day neonatal mortality of more than 3 standard errors from the null, equivalent to $P<0.0027,5455$ which in conjunction with other available evidence would be likely to change the practice of most clinicians worldwide. ${ }^{57}$

\section{Ethics and regulatory compliance}

The study will be conducted according to the International Conference on Harmonization Guidelines for Good Clinical Practice. The study will comply with all applicable laws and regulations and the principles laid down by the World Medical Association in the Declaration of Helsinki 2013. It is registered in the Australian and New Zealand Clinical Trial Registry and ethical and regulatory approvals will be obtained before it begins.

\section{Rationale for an IPD PMA to be coordinated by an international iSEARCH Consortium}

While the first Australian iSEARCH Phase 3 RCT in 3200 women has $80 \%$ power to show a reduction of $35 \%$ in the relative risk of its primary composite endpoint, it lacks adequate power to show (a) a more moderate, but clinically important reduction of $20 \%$ in the relative risk of this outcome; ${ }^{57}$ (b) whether Sildenafil is similarly effective in important subgroups of participants in different settings; and (c) clinically relevant differences in rarer, but critically important outcomes such as intrapartum stillbirth, or neonatal or maternal death. We therefore outline the rationale for (i) an individual participant data prospective meta-analysis in countries with low perinatal mortality rates and (ii) a mega-trial in countries with moderate or high perinatal mortality rates, to be undertaken by a global alliance to be known as the international iSEARCH Collaboration.

\section{What is an Individual Participant Data Prospective Meta-Analysis (IPD PMA)?}

In an IPD PMA, studies are included in a meta-analysis before their results are known. ${ }^{36}$ An IPD PMA is like an international megatrial, but less resource-intense for individual countries and funders. IPD PMAs have been described as next generation systematic reviews because they reduce key problems of traditional retrospective aggregate data meta-analyses such as publication bias, selective reporting bias and incompatible definitions of study outcomes which may otherwise lead to missing values, inability to 
synthesise all relevant data and consequent research waste. ${ }^{36}$ Because data is centrally collected and checked followed by reanalysis of the original, line-by-line data of all randomised patients from each of the trials, IPD PMAs offer many advantages over traditional retrospective aggregate data meta-analysis. The resulting analyses in IPD PMAs can (i) increase statistical power to detect meaningful effects and interactions; (ii) more reliably determine how benefits and harms vary according to individual risk factors; (iii) harmonise data collection and outcomes across the collaboration and agree on common core outcomes to be collected by all trials to provide more consistency and standardisation of results thus minimising research waste; and (iv) undertake robust subgroup analyses to examine potential differential intervention effects. Conducting an IPD PMA rather than a large multi-centre RCT also allows each contributing RCT to be funded independently, circumventing the need to fund a single, often financially prohibitive mega-trial, while achieving comparable statistical power. It also allows each contributing RCT the flexibility to answer additional local questions or modify procedures to reflect local practice. Ensuring that future RCTs to test questions addressing disability-free survival and/or mortality are planned, executed, and interpreted through IPD PMAs represents a major conceptual advance in perinatal medicine. ${ }^{5859}$

The IPD PMA outlined below will be conducted by an alliance known as the international iSEARCH Collaboration, which will include a central steering committee responsible for leading the PMA and managing the collaboration, a group responsible for data management, processing and synthesis, and representatives from each RCT, who will be involved in decisions on the protocol, analysis, and interpretation of the results. The iSEARCHCollaboration will establish a joint, overarching international Data Monitoring Committee, which will include the Chair or a representative of the IDSMCs of each contributing RCT, to receive synthesised data from all included studies at pre-specified times. Detailed protocols and statistical analysis plans for the two PMAs will be published with input from all participating trialists and collaborators, developing the outlines presented here.

I: IPD PMA of iSEARCH RCTs in high income countries with low perinatal mortality rates.

This IPD PMA will include the first iSEARCH Phase 3 RCT whose protocol is described in this paper. Additional Phase 3 iSEARCH RCTs are being planned in Australia and other countries with low perinatal mortality rates and, if funded by NHMRC in Australia and other agencies, are likely to begin before the first iSEARCHRCT completes recruitment. This would fulfil the scenario of a de novo PMA of RCTs beginning at different stages, ${ }^{36}$ like that conducted by the five oxygen saturation targeting trials of the NeOProM Collaboration, 606162 which was formed after the first $\mathrm{RCT}^{63}$ was about to begin and the others were in the early planning stages. ${ }^{64-66}$ Thus, new trials will be eligible to join the IPD PMA up until the point when the first Australian iSEARCH trial has published its primary outcome results, currently expected to be in 2025. Because we estimate that the incidence of the primary composite endpoint of this PMA in high income countries is $7 \%$, to demonstrate a $20 \%$ reduction in the relative risk of this outcome from 7-5.6\% with 90\% power would require all iSEARCHRCTs in Australia and other HICs to enrol 14,000 participants (Table 2, scenario 2). Under the same assumptions, if the incidence of the primary composite endpoint in HICs varied between $5 \%$ and $9 \%$, the total sample size required in HICs might vary between about 20,000 and 10,000 respectively (Table 2, scenarios 3 and 4).

Should we wait for the results of the first iSEARCH RCT before seeking further funding for a second Australian RCT and additional Phase 3 RCTs? The sample size of 3200 in the current iSEARCH RCT yields less than $50 \%$ power to detect a moderate and realistic $20 \%$ reduction in its primary composite outcome. An inconclusive result therefore may well represent a false negative conclusion. Such uncertainty could only be resolved by achieving a larger sample. Waiting for the results of the current iSEARCH $R C T$ could thus delay obtaining a definitive result by several years. On the other hand, if it or the IPD PMA to which it contributes, clearly demonstrates a relative reduction in their primary composite outcome in countries with low perinatal mortality rates, it could be stopped early, and Sildenafil introduced into routine intrapartum care.

II: Rationale for an iSEARCH mega-trial in countries with moderate or high perinatal mortality rates.

As the combined incidence of intrapartum stillbirth and 28-day neonatal mortality is rare $(<1 \%)$ in high-income countries with low perinatal mortality rates, a multi-centre RCT or IPD PMA might require hundreds of thousands of women for sufficient statistical power to detect a moderate reduction in this endpoint. This question is thus better answered by studies in low or middle-income countries with moderate or high perinatal mortality rates, where the incidence of intrapartum stillbirth or neonatal mortality is much higher. 
Collecting all ten component outcomes of the primary composite endpoint of the Australian iSEARCH RCT would be problematic in countries with moderate or high perinatal mortality rates, where the infrastructure and expertise to determine umbilical artery $\mathrm{pH}$, diagnose persistent pulmonary hypertension or provide neonatal respiratory support or admission to a neonatal intensive care unit are not consistently available. Conversely, the combined incidence of intrapartum stillbirth ${ }^{67} 68$ or 7-day neonatal mortality ${ }^{69}$

70 is considerably higher in low resource settings, making it logical and feasible to adopt this as the primary composite endpoint of a mega-trial in these countries. ${ }^{71}$ Assuming a control rate of $2 \%$ for a primary composite endpoint of intrapartum stillbirth and 7-day neonatal mortality, a RCT of Sildenafil vs placebo contributing to the IPD PMA in countries with moderate or high perinatal mortality rates might need 14,000 participants to demonstrate a $35 \%$ reduction in the relative risk of this outcome with two tailed statistical significance of $5 \%$ and $90 \%$ power. (Table 2, scenario 5). Assuming the same rates of drop out and loss to follow up, detecting a more moderate, but still clinically important relative risk reduction of $20 \%$ with similar precision might require about 50,000 women. (Table 2, scenario 6). Under the same assumptions, if the incidence of the composite outcome of intrapartum stillbirth or 7-day neonatal mortality varied between $1.2 \%$ and $2.8 \%$, the total sample size required in countries with moderate or high perinatal mortality rates would vary between about 85,000 and 36,000 respectively, (Table 2, scenarios 7 and 8 ). Achieving such numbers will require highly streamlined processes to ensure fast recruitment with minimal data collection, ${ }^{572}$ (Table 3 ) as in the international mega-trials which each enrolled tens of thousands of patients with suspected myocardial infarction, ${ }^{6-9}$ the MAGPIE trial ${ }^{72}$ of magnesium sulphate in severe pre-eclampsia, which enrolled 10,141 women in 33 countries in 3.5 years, and the UK RECOVERY ${ }^{5}$ and WHO SOLIDARITY ${ }^{31}$ trials.

\section{III: Role of the ALPHA Collaboration in advancing randomised studies of mortality and disability}

A key challenge for future perinatal trials is how to enrol the numbers needed to find moderate, but clinically relevant, improvements in healthy survival. ${ }^{73}$ The ALPHA Collaboration ${ }^{74-77}$ (www.alphacollaboration.com) will work with other organisations to identify questions of high priority to stakeholders worldwide for perinatal trials addressing mortality as the primary outcome and focus globally collaborative efforts on rapidly answering those questions in a new generation of low-cost, mega-trials and prospective meta-analyses of trials enrolling from 5,000 to 50,000 or more participants, as is planned by the iSEARCH Trials. Randomised perinatal mega-studies of this size will also yield considerably more precise and reliable estimates of disability in survivors than has previously been typical - a major benefit.

\section{Conclusion}

Our proposal for a comprehensive evaluation of the effectiveness of Sildenafil to reduce the risk of fetal distress and its consequences in term labour through an IPD PMA of RCTs and a mega-trial in different settings represents a major conceptual advance in achieving large scale randomised evidence in perinatal medicine. The results will be highly relevant to clinicians and guideline developers globally.

iSEARCH is the world's first Phase 3 trial to re-purpose Sildenafil, a widely available, well characterised, affordable, off-patent vasodilator, by evaluating whether, compared to placebo, it improves perinatal and maternal outcomes by reducing operative birth for fetal distress. We will also maintain contact with participating women to collect longer-term outcome data and link with relevant national databases as part of separately funded studies. This is a major area of unmet need. ${ }^{7879}$ Our chosen primary endpoints are all related to intrapartum hypoxia. ${ }^{2580}$ If our hypotheses are proven, Sildenafil will reduce perinatal mortality and/or severe neonatal morbidity, leading to wide implementation in countries with low, moderate or high perinatal mortality rates. This will directly benefit regions that experience the highest rates of perinatal morbidity and mortality thus improving disparities in health outcomes. Intrapartum stillbirths in particular, account for 1 in 2 of all stillbirths, of which almost $98 \%$ occur in countries with moderate or high perinatal mortality rates. ${ }^{81}$ If Sildenafil proves to be of benefit, it will reduce the global health burden attributable to birth asphyxia. If the iSEARCH trials show that Sildenafil does not reduce perinatal morbidity and mortality but confirm that it reduces emergency operative birth, this secondary evidence may also drive introduction of Sildenafil into clinical practice. 
Confirmation of our hypotheses may lead to early translation into practice worldwide, improve management of women in labour, reduce healthcare costs and prevent or reduce serious, life-changing perinatal and maternal adverse outcomes. More broadly, it could facilitate an era of large-scale randomised evidence in perinatal care which could identify interventions achieving healthy survival in infants and women more rapidly and affordably than ever before.

\section{Declarations}

\section{Ethics and dissemination}

The Australian iSEARCH RCT has been approved by Hunter New England Ethic Committee (Ref Number 2020/ETH02791). Each component trial within the iSEARCH Collaboration will be approved by relevant local, regional or national Human Research Ethics Committee. We plan to disseminate the results of this trial via presentations at clinical, academic and scientific meetings as well as peer reviewed journals. We will adhere to all relevant reporting guidelines

\section{Authors' contributions}

SK wrote the first draft. SK and WTM contributed equally to the manuscript. All authors and collaborators reviewed and approved the final version before submission.

\section{Funding statement}

This work was supported by the Australian Medical Research Future Fund, grant number APP1199329.

\section{Competing interest statement}

None of the authors have any competing interests to declare.

\section{Trial Registration}

iSEARCH is registered with the Australian New Zealand Clinical Trials Registry (ACTRN12615000319572) and the Therapeutics Goods Administration of Australia.

\section{References}

1. Sterne JAC, Savovic J, Page MJ, et al. RoB 2: a revised tool for assessing risk of bias in randomised trials. BMJ 2019;366:I4898. doi: 10.1136/bmj.14898

2. Liberati A, Altman DG, Tetzlaff J, et al. The PRISMA statement for reporting systematic reviews and meta-analyses of studies that evaluate healthcare interventions: explanation and elaboration. BMJ 2009;339:b2700. doi: 10.1136/bmj.b2700

3. Booth A, Clarke M, Ghersi D, et al. An international registry of systematic-review protocols. Lancet 2011;377(9760):108-9. doi: 10.1016/S0140-6736(10)60903-8

4. Guyatt $\mathrm{GH}$, Oxman $A D$, Vist GE, et al. GRADE: an emerging consensus on rating quality of evidence and strength of recommendations. BMJ 2008;336(7650):924-6. doi: 10.1136/bmj.39489.470347.AD

5. Recovery Collaborative Group. Horby P, Lim WS, Emberson JR et al. Dexamethasone in Hospitalized Patients with Covid-19. N Engl J Med 2021; 384: 693-704

6. Randomised trial of intravenous atenolol among 16027 cases of suspected acute myocardial infarction: ISIS-1. First International Study of Infarct Survival Collaborative Group. Lancet 1986;2(8498):57-66.

7. Randomised trial of intravenous streptokinase, oral aspirin, both, or neither among 17,187 cases of suspected acute myocardial infarction: ISIS-2. ISIS-2 (Second International Study of Infarct Survival) Collaborative Group. Lancet 1988;2(8607):349-60. [published Online First: 1988/08/13] 
8. ISIS-3: a randomised comparison of streptokinase vs tissue plasminogen activator vs anistreplase and of aspirin plus heparin vs aspirin alone among 41,299 cases of suspected acute myocardial infarction. ISIS-3 (Third International Study of Infarct Survival) Collaborative Group. Lancet 1992;339(8796):753-70.

9. ISIS-4: a randomised factorial trial assessing early oral captopril, oral mononitrate, and intravenous magnesium sulphate in 58,050 patients with suspected acute myocardial infarction. ISIS-4 (Fourth International Study of Infarct Survival) Collaborative Group. Lancet 1995;345(8951):669-85. [published Online First: 1995/03/18]

10. Ayres-de-Campos D, Arulkumaran S, Panel FIFMEC. FIGO consensus guidelines on intrapartum fetal monitoring: Physiology of fetal oxygenation and the main goals of intrapartum fetal monitoring. Int J Gynaecol Obstet 2015;131(1):5-8. doi: 10.1016/j.ijgo.2015.06.018 [published Online First: 2015/10/05]

11. Turner JM, Mitchell MD, Kumar SS. The physiology of intrapartum fetal compromise at term. Am J Obstet Gynecol 2020;222(1):17-26. doi: 10.1016/j.ajog.2019.07.032

12. Maltepe E, Fisher SJ. Placenta: the forgotten organ. Annu Rev Cell Dev Biol 2015;31:523-52. doi: 10.1146/annurev-cellbio100814-125620

13. Janbu T, Nesheim BI. Uterine artery blood velocities during contractions in pregnancy and labour related to intrauterine pressure. Br J Obstet Gynaecol 1987;94(12):1150-5. [published Online First: 1987/12/01]

14. Lear CA, Wassink G, Westgate JA, et al. The peripheral chemoreflex: indefatigable guardian of fetal physiological adaptation to labour. J Physiol 2018;596(23):5611-23. doi: 10.1113/JP274937

15. Hilder L, Zhichao Z, Parker M, et al. Australia's mothers and babies 2012. Perinatal statistics series no. 30. Cat. no. PER 69. Canberra: AlHW 2014

16. Badawi N, Keogh JM. Causal pathways in cerebral palsy. J Paediatr Child Health 2013;49(1):5-8. doi: 10.1111/jpc.12068

17. Graham EM, Ruis KA, Hartman AL, et al. A systematic review of the role of intrapartum hypoxia-ischemia in the causation of neonatal encephalopathy. Am J Obstet Gynecol 2008;199(6):587-95. doi: 10.1016/j.ajog.2008.06.094

18. Blencowe H, Cousens S, Jassir FB, et al. National, regional, and worldwide estimates of stillbirth rates in 2015 , with trends from 2000: a systematic analysis. Lancet Glob Health 2016;4(2):e98-e108. doi: 10.1016/S2214-109X(15)00275-2 [published Online First: 2016/01/23]

19. Kurinczuk JJ, White-Koning M, Badawi N. Epidemiology of neonatal encephalopathy and hypoxic-ischaemic encephalopathy. Early Hum Dev 2010;86(6):329-38. doi: 10.1016/j.earlhumdev.2010.05.010 [published Online First: 2010/06/18]

20. Paauw ND, Terstappen F, Ganzevoort W, et al. Sildenafil During Pregnancy: A Preclinical Meta-Analysis on Fetal Growth and Maternal Blood Pressure. Hypertension 2017;70(5):998-1006. doi: 10.1161/HYPERTENSIONAHA.117.09690

21. Ramesar SV, Mackraj I, Gathiram P, et al. Sildenafil citrate decreases sFlt-1 and sEng in pregnant I-NAME treated SpragueDawley rats. Eur J Obstet Gynecol Reprod Biol 2011;157(2):136-40. doi: 10.1016/j.ejogrb.2011.03.005

22. Wareing M, Myers JE, O'Hara M, et al. Sildenafil citrate (Viagra) enhances vasodilatation in fetal growth restriction. J Clin Endocrinol Metab 2005;90(5):2550-5. doi: 10.1210/jc.2004-1831

23. Turner JM, Russo F, DePrest J, Mol BW, Kumar S. Phosphodiesterase-5 inhibitors in Pregnancy: Systematic review and metaanalysis of maternal and perinatal safety and clinical outcomes. Am J Obstet Gynecol. 2021 Jun 8;S0002-9378(21)00637-2. doi: 10.1016/j.ajog.2021.06.006. Online ahead of print.

24. Turner J, Dunn L, Tarnow Mordi W, et al. Safety and efficacy of sildenafil citrate to reduce operative birth for intrapartum fetal compromise at term: A Phase 2 Randomized Controlled Trial. Am J Obstet Gynecol 2020 doi: 10.1016/j.ajog.2020.01.025 [published Online First: Jan 2020]

25. Grobman WA, Rice MM, Reddy UM, et al. Labor Induction versus Expectant Management in Low-Risk Nulliparous Women. N Engl J Med 2018;379(6):513-23. doi: 10.1056/NEJMoa1800566

26. Djulbegovic B, Kumar A, Magazin A, et al. Optimism bias leads to inconclusive results-an empirical study. J Clin Epidemiol 2011;64(6):583-93. doi: 10.1016/j.jclinepi.2010.09.007

27. Fayers PM, Cuschieri A, Fielding J, et al. Sample size calculation for clinical trials: the impact of clinician beliefs. Br J Cancer 2000;82(1):213-9. doi: 10.1054/bjoc.1999.0902 
28. Zakeri K, Noticewala S, Vitzthum L, et al. 'Optimism bias' in contemporary national clinical trial network phase III trials: are we improving? Annals of oncology: official journal of the European Society for Medical Oncology / ESMO 2018;29(10):2135-39. doi: 10.1093/annonc/mdy340

29. Chalmers I, Matthews R. What are the implications of optimism bias in clinical research? Lancet 2006;367(9509):449 - 50. doi: 10.1016/S0140-6736(06)68153-1

30. Sealed envelope. Trial sample size calculator. https://www.sealedenvelope.com/power/ accessed 24 Jan 2018.

31. W. H. O. Solidarity Trial Consortium. Pan H, Peto R, Henao-Restrepo AM et al. Repurposed Antiviral Drugs for Covid-19 Interim WHO Solidarity Trial Results. N Engl J Med 2021; 384:497-511. doi: 10.1056/NEJMoa2023184

32. Burki TK. Completion of clinical trials in light of COVID-19. The Lancet Respiratory medicine 2020;8(12):1178-80. doi: 10.1016/S2213-2600(20)30460-4

33. WHO Rapid Evidence Appraisal for COVID-19 Therapies Working Group, Sterne JAC, Murthy S, Diaz JV, et al. Association Between Administration of Systemic Corticosteroids and Mortality Among Critically III Patients With COVID-19: A Metaanalysis. JAMA 2020 doi: 10.1001/jama.2020.17023

34. Oladapo OT, Vogel JP, Piaggio G, et al. Antenatal Dexamethasone for Early Preterm Birth in Low-Resource Countries. N Engl J Med 2020 doi: 10.1056/NEJMoa2022398

35. Groom K, Ganzevoort W, Alfirevic Z, et al. Clinicians should stop prescribing sildenafil for fetal growth restriction (FGR): comment from the STRIDER Consortium. Ultrasound in obstetrics \& gynecology: the official journal of the International Society of Ultrasound in Obstetrics and Gynecology 2018;52(3):295.

36. Seidler AL, Hunter KE, Cheyne S, et al. A guide to prospective meta-analysis. BMJ 2019;367:I5342. doi: 10.1136/bmj.I5342

37. Taylor D, Kenyon S, Tarnow-Mordi W. Infection and preterm labour. Br J Obstet Gynaecol 1997;104(12):1338-40. [published Online First: 1998/01/09]

38. Peto R, Baigent C. Trials: the next 50 years. Large scale randomised evidence of moderate benefits. BMJ 1998;317(7167):1170-1.

39. Von Dadelszen P, Dwinnell S, Magee L, et al. Sildenafil citrate therapy for severe early-onset intrauterine growth restriction. BJOG: An International Journal of Obstetrics \& Gynaecology 2011;118(5):624-28.

40. Yu LM, Hey E, Doyle LW, et al. Evaluation of the Ages and Stages Questionnaires in identifying children with neurosensory disability in the Magpie Trial follow-up study. Acta Paediatr 2007;96(12):1803-8. doi: 10.1111/j.1651-2227.2007.00517.x [published Online First: 2007/11/01]

41. Kenyon S, Pike K, Jones DR, et al. Childhood outcomes after prescription of antibiotics to pregnant women with preterm rupture of the membranes: 7-year follow-up of the ORACLE I trial. Lancet 2008;372(9646):1310-8. doi: 10.1016/S01406736(08)61202-7

42. Kenyon S, Pike K, Jones DR, et al. Childhood outcomes after prescription of antibiotics to pregnant women with spontaneous preterm labour: 7-year follow-up of the ORACLE II trial. Lancet 2008;372(9646):1319-27. doi: 10.1016/S01406736(08)61203-9

43. Gamble C, Krishan A, Stocken D, et al. Guidelines for the Content of Statistical Analysis Plans in Clinical Trials. JAMA 2017;318(23):2337-43. doi: 10.1001/jama.2017.18556

44. Schulz KF, Altman DG, Moher D, et al. CONSORT 2010 statement: updated guidelines for reporting parallel group randomised trials. BMJ 2010;340:c332. doi: 10.1136/bmj.c332

45. Collins GS, Reitsma JB, Altman DG, et al. Transparent reporting of a multivariable prediction model for individual prognosis or diagnosis (TRIPOD): the TRIPOD statement. BMJ 2015;350:g7594. doi: 10.1136/bmj.g7594 [published Online First: 2015/01/09]

46. Tarnow-Mordi WO, Abdel-Latif ME, Martin A, et al. The effect of lactoferrin supplementation on death or major morbidity in very low birthweight infants (LIFT): a multicentre, double-blind, randomised controlled trial. Lancet Child Adolesc Health 2020;4(6):444-54 (with online Supplementary Appendix pp S1-S44). doi: 10.1016/S2352-4642(20)30093-6

47. Martin A, Ghadge A, Manzoni P, et al. Protocol for the Lactoferrin Infant Feeding Trial (LIFT): a randomised trial of adding lactoferrin to the feeds of very-low birthweight babies prior to hospital discharge. Statistical Analysis Plan: esupplemental-2.

Page $12 / 25$ 
bmjopen-2018-October-8-10-inline-supplementary-material-2. BMJ open 2018;8(10):e023044. doi: 10.1136/bmjopen-2018023044

48. Pocock SJ, Stone GW. The Primary Outcome Fails - What Next? N Engl J Med 2016;375(9):861-70. doi: 10.1056/NEJMra1510064

49. Pocock SJ, Stone GW. The Primary Outcome Is Positive - Is That Good Enough? N Engl J Med 2016;375(10):971-9. doi: 10.1056/NEJMra1601511

50. Groom KM, McCowan LM, Mackay LK, et al. STRIDER NZAus: a multicentre randomised controlled trial of sildenafil therapy in early-onset fetal growth restriction. BJOG 2019 doi: 10.1111/1471-0528.15658

51. Sharp A, Cornforth C, Jackson R, et al. Maternal sildenafil for severe fetal growth restriction (STRIDER): a multicentre, randomised, placebo-controlled, double-blind trial. Lancet Child Adolesc Health 2018;2(2):93-102. doi: 10.1016/S23524642(17)30173-6

52. Pels A, Derks J, Elvan-Taspinar A, et al. Maternal Sildenafil vs Placebo in Pregnant Women With Severe Early-Onset Fetal Growth Restriction: A Randomized Clinical Trial. JAMA Netw Open 2020;3(6):e205323. doi:

10.1001/jamanetworkopen.2020.5323

53. Sharp A, Cornforth C, Jackson R, et al. Mortality in the UK STRIDER trial of sildenafil therapy for the treatment of severe earlyonset fetal growth restriction. Lancet Child Adolesc Health 2019;3(3):e2-e3. doi: 10.1016/S2352-4642(19)30020-3

54. Haybittle JL. Repeated assessment of results in clinical trials of cancer treatment. Br J Radiol 1971;44(526):793-7. doi: 10.1259/0007-1285-44-526-793

55. Peto R, Pike MC, Armitage $\mathrm{P}$, et al. Design and analysis of randomized clinical trials requiring prolonged observation of each patient. I. Introduction and design. Br J Cancer 1976;34(6):585-612.

56. Geller NL, Pocock SJ. Interim analyses in randomized clinical trials: ramifications and guidelines for practitioners. Biometrics 1987;43(1):213-23.

57. Group RC, Horby P, Lim WS, et al. Dexamethasone in Hospitalized Patients with Covid-19 - Preliminary Report. N Engl J Med 2020 doi: 10.1056/NEJMoa2021436

58. loannidis JP. Meta-research: The art of getting it wrong. Res Synth Methods 2010;1(3-4):169-84. doi: 10.1002/jrsm.19

59. Halpern SD, Karlawish JH, Berlin JA. The continuing unethical conduct of underpowered clinical trials. JAMA 2002;288(3):358-62.

60. Cole $\mathrm{CH}$, Wright KW, Tarnow-Mordi W, et al. Resolving our uncertainty about oxygen therapy. Pediatrics 2003;112(6 Pt 1):1415-9. [published Online First: 2003/12/05]

61. Askie LM, Brocklehurst P, Darlow BA, et al. NeOProM: Neonatal Oxygenation Prospective Meta-analysis Collaboration study protocol. BMC Pediatr 2011;11:6. doi: 10.1186/1471-2431-11-6 [published Online First: 2011/01/18]

62. Askie LM, Darlow BA, Finer N, et al. Association Between Oxygen Saturation Targeting and Death or Disability in Extremely Preterm Infants in the Neonatal Oxygenation Prospective Meta-analysis Collaboration. JAMA 2018;319(21):2190 - 201. doi: 10.1001/jama.2018.5725

63. Carlo WA, Finer NN, Walsh MC, et al. Target ranges of oxygen saturation in extremely preterm infants. N Engl J Med 2010;362(21):1959-69. doi: 10.1056/NEJMoa0911781 [published Online First: 2010/05/18]

64. Schmidt B, Whyte RK, Asztalos EV, et al. Effects of targeting higher vs lower arterial oxygen saturations on death or disability in extremely preterm infants: a randomized clinical trial. JAMA 2013;309(20):2111-20. doi: 10.1001/jama.2013.5555

65. Darlow BA, Marschner SL, Donoghoe M, et al. Randomized controlled trial of oxygen saturation targets in very preterm infants: two year outcomes. J Pediatr 2014;165(1):30-35 e2. doi: 10.1016/j.jpeds.2014.01.017

66. Tarnow Mordi W, Stenson, B. for BOOST II Australia and BOOST II UK Collaborative Groups. Outcomes of two trials of oxygen saturation targets in preterm infants. Web Supplement.

http://www.nejm.org/doi/suppl/10.1056/NEJMoa1514212/suppl_file/nejmoa1514212_appendix.pdf. N Engl J Med 2016;374:749 - 60 .

67. Report of the UN Inter-agency Group for Child Mortality Estimation. A Neglected Tragedy The global burden of stillbirths. 2020 
68. McClure EM, Saleem S, Goudar SS, et al. Stillbirth rates in low-middle income countries 2010-2013: a population-based, multi-country study from the Global Network. Reprod Health 2015;12 Suppl 2:S7. doi: 10.1186/1742-4755-12-S2-S7 [published Online First: 2015/06/13]

69. Saleem S, McClure EM, Goudar SS, et al. A prospective study of maternal, fetal and neonatal deaths in low- and middleincome countries. Bulletin of the World Health Organization 2014;92(8):605-12. doi: 10.2471/BLT.13.127464

70. Alkema L, Chou D, Hogan D, et al. Global, regional, and national levels and trends in maternal mortality between 1990 and 2015, with scenario-based projections to 2030: a systematic analysis by the UN Maternal Mortality Estimation Inter-Agency Group. Lancet 2016;387(10017):462-74. doi: 10.1016/S0140-6736(15)00838-7 [published Online First: 2015/11/21]

71. Althabe F, Belizan JM, McClure EM, et al. A population-based, multifaceted strategy to implement antenatal corticosteroid treatment versus standard care for the reduction of neonatal mortality due to preterm birth in low-income and middle-income countries: the ACT cluster-randomised trial. Lancet 2015;385(9968):629-39. doi: 10.1016/S0140-6736(14)61651-2

72. Altman D, Carroli G, Duley L, et al. Do women with pre-eclampsia, and their babies, benefit from magnesium sulphate? The Magpie Trial: a randomised placebo-controlled trial. Lancet 2002;359(9321):1877-90.

73. Tarnow-Mordi W, Kumar P, Kler N. Neonatal trials need thousands, not hundreds, to change global practice. Acta Paediatr 2011;100(3):330-3. doi: 10.1111/j.1651-2227.2011.02141.x

74. Fogarty M, Osborn DA, Askie L, et al. Delayed vs early umbilical cord clamping for preterm infants: a systematic review and meta-analysis. Am J Obstet Gynecol 2018;218(1):1-18. doi: 10.1016/j.ajog.2017.10.231

75. Turner J, Dunn L, Tarnow-Mordi W, et al. Safety and efficacy of sildenafil citrate to reduce operative birth for intrapartum fetal compromise at term: a phase 2 randomized controlled trial. Am J Obstet Gynecol 2020;222(5):401-14. doi:

10.1016/j.ajog.2020.01.025

76. Tarnow-Mordi W, Cruz M, Morris JM, et al. RCT evidence should drive clinical practice: A day without randomisation is a day without progress. BJOG 2017;124(4):613. doi: 10.1111/1471-0528.14468

77. Soll RF, Ovelman C, McGuire W. The future of Cochrane Neonatal. Early Hum Dev 2020;150:105191. doi: 10.1016/j.earlhumdev.2020.105191

78. Liu L, Oza S, Hogan D, et al. Global, regional, and national causes of child mortality in 2000-13, with projections to inform post-2015 priorities: an updated systematic analysis. Lancet 2015;385(9966):430-40. doi: 10.1016/S0140-6736(14)61698-6

79. Stemming the global caesarean section epidemic. Lancet 2018;392(10155):1279. doi: 10.1016/S0140-6736(18)32394-8

80. Webbe JWH, Duffy JMN, Afonso E, et al. Core outcomes in neonatology: development of a core outcome set for neonatal research. Arch Dis Child Fetal Neonatal Ed 2020;105(4):425-31. doi: 10.1136/archdischild-2019-317501

81. Lawn JE, Blencowe H, Waiswa P, et al. Stillbirths: rates, risk factors, and acceleration towards 2030. Lancet 2016;387(10018):587-603. doi: 10.1016/S0140-6736(15)00837-5 [published Online First: 2016/01/23]

82. Mozooni M, Preen DB, Pennell CE. Stillbirth in Western Australia, 2005-2013: the influence of maternal migration and ethnic origin. Med J Aust 2018;209(9):394-400.

83. Giussani DA. The fetal brain sparing response to hypoxia: physiological mechanisms. J Physiol 2016;594(5):1215-30. doi: 10.1113/JP271099 [published Online First: 2015/10/27]

84. Persson M, Razaz N, Tedroff K, et al. Five and 10 minute Apgar scores and risks of cerebral palsy and epilepsy: population based cohort study in Sweden. BMJ 2018;360:k207. doi: 10.1136/bmj.k207

85. Yeh P, Emary K, Impey L. The relationship between umbilical cord arterial pH and serious adverse neonatal outcome: analysis of 51,519 consecutive validated samples. BJOG 2012;119(7):824-31. doi: 10.1111/j.1471-0528.2012.03335.x

86. Laptook AR, Shankaran S, Tyson JE, et al. Effect of Therapeutic Hypothermia Initiated After 6 Hours of Age on Death or Disability Among Newborns With Hypoxic-Ischemic Encephalopathy: A Randomized Clinical Trial. JAMA 2017;318(16):1550-60. doi: 10.1001/jama.2017.14972

87. Thygesen SK, Olsen M, Ostergaard JR, et al. Respiratory distress syndrome in moderately late and late preterm infants and risk of cerebral palsy: a population-based cohort study. BMJ open 2016;6(10):e011643. doi: 10.1136/bmjopen-2016-011643

88. Smith GC, Wood AM, White IR, et al. Neonatal respiratory morbidity at term and the risk of childhood asthma. Arch Dis Child 2004;89(10):956-60. doi: 10.1136/adc.2003.045971

Page 14/ 25 
89. Lipkin PH, Davidson D, Spivak L, et al. Neurodevelopmental and medical outcomes of persistent pulmonary hypertension in term newborns treated with nitric oxide. J Pediatr 2002;140(3):306-10.

90. Beligere N, Rao R. Neurodevelopmental outcome of infants with meconium aspiration syndrome: report of a study and literature review. J Perinatol 2008;28 Suppl 3:S93-101. doi: 10.1038/jp.2008.154

91. Cordoba G, Schwartz L, Woloshin S, et al. Definition, reporting, and interpretation of composite outcomes in clinical trials: systematic review. BMJ 2010;341:c3920. doi: 10.1136/bmj.c3920

92. Ferreira-Gonzalez I, Permanyer-Miralda G, Busse JW, et al. Methodologic discussions for using and interpreting composite endpoints are limited, but still identify major concerns. J Clin Epidemio/ 2007;60(7):651-7; discussion 58-62. doi: 10.1016/j.jclinepi.2006.10.020 [published Online First: 2007/06/19]

93. Morley CJ, Davis PG, Doyle LW, et al. Nasal CPAP or intubation at birth for very preterm infants. N Engl J Med 2008;358(7):700-8. doi: 10.1056/NEJMoa072788 [published Online First: 2008/02/15]

94. Askie LM, Henderson-Smart DJ, Irwig L, et al. Oxygen-saturation targets and outcomes in extremely preterm infants. $\mathrm{N}$ Engl $\mathrm{J}$ Med 2003;349(10):959-67. doi: 10.1056/NEJMoa023080 [published Online First: 2003/09/05]

95. Brocklehurst P, Farrell B, King A, et al. Treatment of neonatal sepsis with intravenous immune globulin. N Engl J Med 2011;365(13):1201-11. doi: 10.1056/NEJMoa1100441 [published Online First: 2011/10/04]

96. Kenyon SL, Taylor DJ, Tarnow-Mordi W. Broad-spectrum antibiotics for preterm, prelabour rupture of fetal membranes: the ORACLE I randomised trial. ORACLE Collaborative Group. Lancet 2001;357(9261):979-88. [published Online First: 2001/04/11]

97. Tarnow-Mordi W, Morris J, Kirby A, et al. Delayed versus Immediate Cord Clamping in Preterm Infants. N Engl J Med 2017;377(25):2445-55. doi: 10.1056/NEJMoa1711281

98. Saigal S, Stoskopf BL, Feeny D, et al. Differences in preferences for neonatal outcomes among health care professionals, parents, and adolescents. JAMA 1999;281(21):1991-7.

99. Consortium WHOST, Pan H, Peto R, et al. Repurposed Antiviral Drugs for Covid-19 - Interim WHO Solidarity Trial Results. N Engl J Med 2020 doi: 10.1056/NEJMoa2023184

100. Gray R, Clarke M, Collins R, et al. Making randomised trials larger: a simple solution? Eur J Surg Oncol 1995;21(2):137-9. doi: 10.1016/s0748-7983(95)90105-1

101. Djulbegovic B, Kumar A, Glasziou P, et al. Medical research: Trial unpredictability yields predictable therapy gains. Nature 2013;500(7463):395-6. doi: 10.1038/500395a

102. Hoffman MK, Goudar SS, Kodkany BS, et al. Low-dose aspirin for the prevention of preterm delivery in nulliparous women with a singleton pregnancy (ASPIRIN): a randomised, double-blind, placebo-controlled trial. Lancet 2020;395(10220):285-93. doi: 10.1016/S0140-6736(19)32973-3

103. Collins R, Bowman L, Landray M, et al. The Magic of Randomization versus the Myth of Real-World Evidence. N Engl J Med 2020;382(7):674-78. doi: 10.1056/NEJMsb1901642

104. Robledo KP, Tarnow-Mordi WO, Rieger I, et al. Effects of delayed versus immediate umbilical cord clamping in reducing death or major disability at 2 years corrected age among very preterm infants (APTS): a multicentre, randomised clinical trial. Lancet Child Adolesc Health 2021 doi: 10.1016/S2352-4642(21)00373-4

105. Sun X, Briel M, Busse JW, et al. Credibility of claims of subgroup effects in randomised controlled trials: systematic review. BMJ 2012;344:e1553. doi: 10.1136/bmj.e1553

106. Damocles Study Group. NHS Health Technology Assessment Programme. A proposed charter for clinical trial data monitoring committees: helping them to do their job well. Lancet 2005;365(9460):711-22. doi: 10.1016/S01406736(05)17965-3

\section{Tables}

Table 1

Primary composite outcome in the Australian iSEARCH Trial

Page 15/25 


\begin{tabular}{|lll|}
\hline Components of composite primary endpointt & Rate* & Association with long term adverse outcome \\
\hline Intrapartum stillbirth ${ }^{82}$ & $0.1 \%$ & - \\
\hline 28 day neonatal mortality 83 & $0.24 \%$ & - \\
\hline Apgar score $<4$ at 5 minutes & $0.5 \%$ & $\uparrow$ risk of cerebral palsy ${ }^{84}$ \\
\hline Umbilical Cord artery $\mathrm{pH}<7.0$ & $2.2 \%$ & $\uparrow$ risk of HIE ${ }^{85}$ \\
\hline Neonatal encephalopathy, Sarnat Grade 2 or 3 & $0.5 \%$ & $\uparrow$ risk of death or disability 86 \\
\hline Neonatal seizures§ & $0.25 \%$ & $\uparrow$ risk of death or disability 86,8 \\
\hline Neonatal respiratory support for $>4$ h & $3.6 \%$ & $\uparrow$ risk of cerebral palsy ${ }^{87}$ \\
\hline Neonatal unit admission for $>48 \mathrm{~h}$ & $4.3 \%$ & $\uparrow$ asthma after term respiratory morbidity ${ }^{88}$ \\
\hline Persistent pulmonary hypertension & $0.04 \%$ & $\uparrow$ risk of death or disability 89 \\
\hline Meconium aspiration & $0.75 \%$ & $\uparrow$ risk of death or disability 90 \\
\hline Total (corrected for overlap) & $7.0 \%$ & \\
\hline
\end{tabular}

tsuitably constructed composite endpoints ${ }^{91} 92$ are often used in multi-centre perinatal RCTs. ${ }^{93-97,98}$

*based on data from Grobman et al, ${ }^{25}$ and the Australia New Zealand Neonatal Network ${ }^{37}$

$\S$ although seizures include non-encephalopathic causes like stroke or metabolic disorders, in a randomised trial, those causes not influenced by Sildenafil will tend to be evenly balanced between study arms and therefore tend not to bias the comparison. In this pragmatic trial, seizures, persistent pulmonary hypertension and meconium aspiration are all defined using local protocols.

\section{Table 2}

Sample sizes of RCTs of sildenafil in labour to show relative risk reductions of $35 \%$ or $20 \%$ in primary composite endpoints in settings with (i) low and (ii) moderate or high perinatal mortality rates. 


\begin{tabular}{|c|c|c|c|c|c|c|c|c|}
\hline \multirow[t]{3}{*}{$\begin{array}{l}\text { Perinatal } \\
\text { mortality } \\
\text { rate } \\
\text { (PMR) }\end{array}$} & \multirow[t]{3}{*}{ Scenario } & \multirow{3}{*}{$\begin{array}{l}\text { Event } \\
\text { rate in } \\
\text { control } \\
\text { group }\end{array}$} & \multirow{3}{*}{$\begin{array}{l}\text { Event } \\
\text { rate in } \\
\text { treated } \\
\text { group } \\
\text { (T) }\end{array}$} & \multirow{3}{*}{$\begin{array}{l}\text { Relative } \\
\text { Risk (or } \\
\text { Risk } \\
\text { Ratio) } \\
\\
\text { (RR=T/C) }\end{array}$} & \multirow{3}{*}{$\begin{array}{l}\text { Relative } \\
\text { Risk } \\
\text { Reduction }\end{array}$} & \multicolumn{3}{|c|}{$\begin{array}{l}\text { Total sample to show effect in a two arm } \\
\text { superiority trial with } 90 \%(\text { or }>80 \% * \text { power at } \\
2 p=0.05 \text {, allowing for non-adherence to protocol } \\
\text { due to:- }\end{array}$} \\
\hline & & & & & & $\begin{array}{l}0 \% \text { dropout or loss to } \\
\text { follow up (perfect } \\
\text { protocol adherence) }\end{array}$ & $\begin{array}{l}2 \% \\
\text { drop- } \\
\text { out }\end{array}$ & $\begin{array}{l}2 \% \text { drop } \\
\text { out and } 5 \% \\
\text { loss to } \\
\text { follow up }\end{array}$ \\
\hline & & & & & & & & \\
\hline \multirow{4}{*}{$\begin{array}{l}\text { (i) Low } \\
\text { PMR }^{+}\end{array}$} & 1 & $7 \%$ & $4.55 \%$ & 0.65 & 0.35 & $2,840 *$ & $2,957 *$ & $3,113^{\star}$ \\
\hline & 2 & $7 \%$ & $5.6 \%$ & 0.8 & 0.2 & 12,652 & 13,174 & 13,867 \\
\hline & 3 & $5 \%$ & $4 \%$ & 0.8 & 0.2 & 18,058 & 18,803 & 19,792 \\
\hline & 4 & $9 \%$ & $7.2 \%$ & 0.8 & 0.2 & 9,650 & 10,048 & 10,577 \\
\hline \multirow{4}{*}{$\begin{array}{l}\text { (ii) } \\
\text { moderate } \\
\text { or high } \\
\text { PMR }\end{array}$} & 5 & $2 \%$ & $1.3 \%$ & 0.65 & 0.35 & 13,914 & 14,488 & 15,250 \\
\hline & 6 & $2 \%$ & $1.6 \%$ & 0.8 & 0.2 & 46,436 & 48,351 & 50,895 \\
\hline & 7 & $1.2 \%$ & $0.96 \%$ & 0.8 & 0.2 & 77,968 & 81,183 & 85,456 \\
\hline & 8 & $2.8 \%$ & $2.24 \%$ & 0.8 & 0.2 & 32,924 & 34,282 & 36,086 \\
\hline \multirow{2}{*}{\multicolumn{9}{|c|}{$\begin{array}{l}\text { t The primary composite endpoin } \\
\text { births) includes ten adverse perina } \\
\text { encephalopathy, seizures, respirat } \\
\text { meconium aspiration or umbilical } \\
{ }^{*} \text { calculated to yield }>80 \% \text { power }\end{array}$}} \\
\hline & & & & & & & & \\
\hline \multicolumn{9}{|c|}{$\begin{array}{l}\text { \$ The primary composite endpoint in low or middle income settings with perinatal mortality rates that are high (>40 per } 1000 \\
\text { births) or moderate (20-40 per } 1000 \text { births }{ }^{71} \text { includes two adverse perinatal events (intrapartum stillbirth, 7-day neonatal } \\
\text { death) } 67-70\end{array}$} \\
\hline
\end{tabular}

Table 3

Suggested approaches to various stakeholders in randomising tens of thousands of women in the iSEARCH Trials Collaboration, derived from mega-trials in myocardial infarction ${ }^{6-9}$ and COVID-195 
For pregnant

women, their

partners and

parent groups
For doctors, midwives,

pharmacists, and other health professionals
For researchers

and trialists
For research

ethics committees and IRBs
For peak bodies, funders, regulators, and policymakers
- Can Sildenafil make birth even safer?

\section{- Why support this?}

It's nice to do some medical research - even if we are swamped.

Thanks to previous research, childbirth has never been safer.

But about 1 in 10 women in labour still need delivery by Caesarean Section, forceps or vacuum for fetal distress.

Sildenafil (Viagra) improves blood flow, so it may slightly increase blood flow to the baby in labour. In one study it reduced emergency deliveries for fetal distress.

This hospital has joined an international study to see if Sildenafil improves the baby's condition at birth.

If you sign up, when labour starts you either get a Sildenafil pill or a dummy pill that looks the same - then up to 2 more pills, 8 hours apart.

Please ask your doctor or midwife if you would like to know more. little work with potentially large benefits.

It may help women and babies around the world.

\section{- Busy clinicians can make a big difference} 20,000 COVID-19 patients was moderately effective in reducing deaths - but hydroxycholoroquine and various antivirals were not ${ }^{57}$ 99 also reduced deaths.

\section{- Tens of thousands of women worldwide may need to join this trial.}

Viagra (Sildenafil) is already widely used for other purposes, mostly not in pregnant women.

A study in women in labour safe for mothers and babies and it reduced emergency
We can do this. It is relatively

Supported by busy clinicians, two randomised trials in over showed that dexamethasone

casirivimab and imdevimab -

https://www.recoverytrial.net/ suggested the drug should be deliveries for fetal distress. ${ }^{75}$ However, the study was too

\section{- Make the trial as simple as possible for staff on the ground.}

Doctors and midwives can only enter most of their eligible patients into randomized studies if it involves almost no extra

work. ${ }^{100}$

Aim to get the whole team of midwives, doctors and other staff wholeheartedly involved.

Get them

motivated, thinking "Yes we can do this. We'll be contributing to something good, and it will be almost no work"

\section{- Constraints on trials of new uses for old drugs need to be risk proportionate.}

Trials of new uses for drugs whose safety profiles are well known, like Viagra, pose less risk than trials of new drugs.

Yet a "one size fits all" approach to requirements for informed consent may make it unfeasible to enrol the tens of thousands that may be needed to detect moderate, but important effects.

For example, Vitamin D, which is available from chemists over the counter without prescription, may moderately improve survival in cardiovascular disease, but a trial to show this might need over 100,000 patients.

\section{the hypothesis too promising}

Don't make

Overoptimism as to how big the treatment effect could be is a great obstacle to realistic medical research.

- Consent forms need to

But such a trial will be impossible if the same level of detailed informed consent is required as is, quite appropriately, needed in a trial of a new drug or vaccine.
- It is reasonable to randomise tens of thousands of women to test treatments that may be used in tens of millions.

Medicines with only moderate effects (like low dose aspirin in myocardial infarction ${ }^{6-9}$ or in first-time pregnancies in countries with moderate or high perinatal mortality rates ${ }^{102}$ ) can still save thousands of lives in common conditions.

Small differences are worth knowing about, if they are there, because they can significantly improve public health.

But requirements for excessive documentation cause many mega-trials to fail.

\section{- Highly streamlined internationa collaboration is needed to protect patients and improve care}

Increased adherence to rules rather than the scientific principles that underlie randomized trials has substantially increased the complexity and cost of trials $^{103}$

One consequence has been increasing difficulty in recruiting patients into trials in many countries.

Obstacles to randomized trials should be removed to facilitate the reliable assessment of existing treatments and to allow new 
- This trial is approved by the hospital's ethics committee

It is not sponsored by the manufacturers of Sildenafil.

\section{- Many questions about care in childbirth remain} unanswered.

Doctors and midwives in this hospital invite you to help answer those questions by taking part in research, so that we can keep improving childbirth for everyone. small to assess effects on the baby reliably.

While it's safe in men and expected to be safe in pregnant women, any effects probably won't be big.

Tens of thousands of women may need to join the trial to find out if it is of any benefit to their infants (as some researchers hope), or if there's any slight unanticipated harm, or if there is no material effect (which trials of new uses for old drugs often disappointingly find).
Treatments are unlikely to be as good as the person who discovered them thinks they are going to be.

But even if a medicine doesn't work very well it can still save thousands of lives.

So small

differences are worth knowing about - if they are there.

\section{- To find moderate benefits, trials need surprisingly large numbers}

To detect a $20 \%$ relative reduction in adverse perinatal outcome from $7 \%$ to $5.6 \%$ with $90 \%$ power would need about 14,000 participants (Table 2).

To detect a

similar reduction in intrapartum stillbirth and/ or neonatal mortality from $2 \%$ to $1.6 \%$ with similar power would need about 50,000.

Such numbers will only be feasible with global collaboration between

\section{disclose the benefits of inclusion in large (Phase III) trials.}

Among the barriers to enrolment are commonly held views that overestimate the risks of large, randomised trials and underestimate their benefits.

But such views are not backed by empirical evidence. For example, in prospective studies of 860 Phase III RCTs in 350,000 people, the result of any one trial was unpredictable but average survival in all participants was slightly better than survival in those allocated usual care. ${ }^{101}$

It may be helpful to ask patients about how hospital websites and research consent forms could explain the benefits of participating in RCTs, in simple, neutral, noncoercive terms. treatments to become available more rapidly. ${ }^{103}$

A new generation of international perinatal trials is needed, to run at least "ten times larger and faster and at one tenth the cost" as envisaged by the ALPHA Collaboration ${ }^{74-76} 104$ www.alphacollaboration.com 
doctors,

midwives,

women and

trialists

worldwide.

Table 4

Suggested best practice from the conduct and analysis of large trials in myocardial infarction ${ }^{6-9}$ 
- Produce clear, attractive training and information materials for participants and staff

(e.g., https://www.recoverytrial.net/ $)^{5}$

Posters in waiting rooms or consulting rooms need to be very simple. $90 \%$ of the work will be in preparing simple information materials for women and training materials on consent and registration for site staff. Consider e-consent to minimise face to face contact and additional visits.

- Programme the website so that it takes $<5 \mathrm{~min}$ for an accredited member of staff to register an eligible woman before labour and $<1 \mathrm{~min}$ to randomise her when labour starts

Work out how online registration can be done beforehand as a non-emergency whenever possible so that, when labour comes, only a short conversation is needed for the woman to confirm or change her mind. If she confirms, randomisation occurs, and a numbered drug pack is allocated from the store kept on labour ward.

\section{- Drug packaging is important.}

Drug packs are kept on labour ward, regularly replenished by pharmacy staff. Never let any hospital run out of drug. Have instructions on the pack, saying what needs to happen.

Assay random samples from drug packs on labour ward to prove that what is labelled as drug really is drug and that placebo really is placebo. Make this checking part of the trial structure.

\section{- Maximise use of electronic technology to address increasing regulatory obstacles}

By simplifying user access to websites and ensuring

forms.

consistent completion of electronic case-report

adherence to protocol and safety procedures.

centralised monitoring

records

complete follow up by linkage to electronic health

All this requires serious programming assistance - ten times more than you might imagine.

- Interpret subgroup and secondary analyses with caution
- Criteria by which the DMC may recommend modifying enrolment

Agree in a charter for the $\mathrm{DMC}^{106}$ that the DMC will advise the Trial Steering Committee if it considers that (a) there is proof beyond reasonable doubt of a real effect on the primary outcome or on mortality and (b) this evidence would change the behaviour of those who are already aware of other trials in this area.

- A fundamental issue is that birth by emergency Caesarean section for fetal distress or instrumental vaginal birth with vacuum or forceps for fetal distress are secondary outcomes

The terms of reference of the DMC should explicitly state that - whether or not there is a difference in CS - the primary outcome of the trial is harm to the fetus. 
Without a strong, sensible, prior reason why a subgroup should fare differently it is difficult to differentiate real from chance differences in outcome among subgroups ${ }^{105}$ or secondary analyses.

For example, in the ISIS-2 trial of 17,187 patients, aspirin substantially reduced mortality overall and in patients born under Libra and Gemini, but was apparently ineffective in those born under Capricorn! ${ }^{7}$

Also, despite their higher risk of mortality, many patients with ST depression today still do not receive clot buster drugs because of a misleadingly negative subgroup analysis for streptokinase in ISIS-2. ${ }^{7}$

\section{Appendix}

The International iSearch Trials Collaboration: 


\begin{tabular}{|c|c|c|}
\hline Name & Research Institute/Hospital & University or Hospital Affiliation \\
\hline $\begin{array}{l}\text { Elizabeth } \\
\text { Asztalos }\end{array}$ & Sunnybrook Research Institute & Sunnybrook Health Sciences Centre \\
\hline Jon Barrett & Obstetrics \& Gynecology, Faculty of Health Sciences & McMaster University \\
\hline Keith Barrington & Sainte Justine University Health Center & Universite de Montreal \\
\hline Michael Belfort & Texas Children's Fetal Centre & $\begin{array}{l}\text { Texas Children's Hospital Pavilion } \\
\text { for Women }\end{array}$ \\
\hline Fran Boyle & Mater Research Institute & University of Queensland \\
\hline Wally Carlo & Children's Hospital of Alabama & University of Alabama, Birmingham \\
\hline Brian Cleary & Rotunda Hospital Dublin & $\begin{array}{l}\text { Royal College of Surgeons in } \\
\text { Ireland: Dublin }\end{array}$ \\
\hline Mahesh Choolani & National University Hospital & National University of Singapore \\
\hline Dipika Deka & & Cloudnine Hospital Bangalore India \\
\hline Richard Derman & $\begin{array}{l}\text { Associate Provost Global Affairs, Director Global Health } \\
\text { Research, }\end{array}$ & $\begin{array}{l}\text { Thomas Jefferson University, } \\
\text { Philadelphia }\end{array}$ \\
\hline Brad DeVries & School of Public Health & University of Sydney \\
\hline $\begin{array}{l}\text { Sangappa } \\
\text { Dhaded }\end{array}$ & & Jawaharlal Nehru Medical College \\
\hline Michael Dibley & School of Public Health & University of Sydney \\
\hline Jon Dorling & University Hospital Southampton & Southampton \\
\hline $\begin{array}{l}\text { Gregory } \\
\text { Duncombe }\end{array}$ & Sunshine Coast University Hospital & University of Queensland \\
\hline Lauren Farrell & Mater Research Institute & University of Queensland \\
\hline Chris Gale & Chelsea and Westminster Hospital & Imperial College London \\
\hline Adrienne Gordon & Faculty of Medicine and Health & University of Sydney \\
\hline Chris Griffin & King Edward Memorial Hospital & University of Western Australia \\
\hline Deborah Harris & School of Nursing, Midwifery and Health Practice & Victoria University of Wellington \\
\hline Amanda Henry & Royal Hospital for Women Sydney & University of NSW \\
\hline Caroline Homer & Burnet Institute & University of Melbourne \\
\hline $\begin{array}{l}\text { Mohammed } \\
\text { Hoque }\end{array}$ & NHMRC Clinical Trials Centre & University of Sydney \\
\hline Tanvir Huda & School of Public Health & University of Sydney \\
\hline Kate Jarrett & Mater Research Institute & University of Queensland \\
\hline Stefan Kane & Royal Women's Hospital & University of Melbourne \\
\hline Helen Kay & Mater Research Institute & University of Queensland \\
\hline Anthony Keech & NHMRC Clinical trials centre & University of Sydney \\
\hline Minesh Khashu & Poole Hospital NHS Foundation Trust & Bournemouth University \\
\hline Elisabeth Kibaru & Nakuru County Hospital & Egerton University, Kenya \\
\hline Kishore Kumar & Kids Clinic India & Cloudnine Hospital Bangalore India \\
\hline
\end{tabular}

Page 23/25 


\begin{tabular}{|c|c|c|}
\hline Angella Liu & Faculty of Medicine and Health & University of Sydney \\
\hline Christoph Lehner & Royal Brisbane \& Women's Hospital & University of Queensland \\
\hline Kei Lui & Royal Hospital for Women & University of New South Wales \\
\hline Sarah McDonald & Obstetrics \& Gynecology, Faculty of Health Sciences & McMaster University \\
\hline $\begin{array}{l}\text { Akhil } \\
\text { Maheshwari }\end{array}$ & Johns Hopkins Children's Centre & Johns Hopkins University \\
\hline $\begin{array}{l}\text { Kassam } \\
\text { Mahomed }\end{array}$ & Ipswich Hospital & University of Queensland \\
\hline Fergal Malone & Rotunda Hospital Dublin & $\begin{array}{l}\text { Royal College of Surgeons in } \\
\text { Ireland: Dublin }\end{array}$ \\
\hline lan Marschner & NHMRC Clinical Trials Centre & University of Sydney \\
\hline Neena Modi & Neonatal Medicine Research Group & Imperial College London \\
\hline Fergal Malone & Rotunda Hospital Dublin & $\begin{array}{l}\text { Royal College of Surgeons in } \\
\text { Ireland: Dublin }\end{array}$ \\
\hline Brett Manley & $\begin{array}{l}\text { Murdoch Children's Research Institute, Royal Women's Hospital } \\
\text { Melbourne }\end{array}$ & University of Melbourne \\
\hline Jonathan Morris & Kolling Institute of Medical Research & University of Sydney \\
\hline JuLee Oei & NHMRC Clinical Trials Centre & University of Sydney \\
\hline Amos Otara & Nakuru County Hospital, Kenya & Egerton University, Kenya \\
\hline Felicity Park & The Hunter Medical Research Institue & University of Sydney \\
\hline Gareth Parry & Department of Pediatric Plastic and Oral Surgery & Boston Children's Hospital \\
\hline $\begin{array}{l}\text { Dharmintra } \\
\text { Pasupathy }\end{array}$ & Westmead Hospital, Sydney Medical School & University of Sydney \\
\hline Himanshu Popat & Children's Hospital Westmead & University of Sydney \\
\hline Shannyn Rosser & Mater Research Institute & University of Queensland \\
\hline Ola Saugstad & Feinberg School of Medicine & Northwestern University \\
\hline $\begin{array}{l}\text { Prakeshkumar } \\
\text { Shah }\end{array}$ & Lunenfeld-Tanenbaum Research Institute & University of Toronto \\
\hline Antonia Shand & Royal Hospital for Women & University of Sydney \\
\hline John Simes & NHMRC Clinical Trials Centre & University of Sydney \\
\hline Roger Soll & University of Vermont Medical Centre & University of Vermont \\
\hline Alan Tita & Center for Women's and Reproductive health & University of Alabama, Birmingham \\
\hline Sally Tracy & $\begin{array}{l}\text { Midwifery and Women's Health Research Unit, Royal Hospital for } \\
\text { Women Sydney }\end{array}$ & University of NSW \\
\hline Tegan Triggs & Mater Research Institute & University of Queensland \\
\hline Jessica Turner & Mater Research Institute & University of Queensland \\
\hline Max Vento & Instituto De Investigacion Sanitaria La Fe & Valencia \\
\hline David Watson & Townsville University Hospital & James Cook University \\
\hline Angela Webster & NHMRC Clinical Trials Centre & University of Sydney \\
\hline
\end{tabular}


